\title{
From Geographic Cluster to Connected Cluster
}

\author{
A connected mechanism research on creative clusters
}

\author{
Junmin Wang \\ College of Mechanical Engineering \\ Donghua Universyty \\ Shanghai, China \\ tidyon@dhu.edu.cn
}

\author{
Shuai Yang \\ College of Mechanical Engineering \\ Donghua Universyty \\ Shanghai, China \\ shamuelyang@163.com
}

\begin{abstract}
Structural distribution of urban industrial resources is a natural result of the long-term development of regional economy. In order to satisfy the need of the content construction around the new formats of creative industries, existing resources are inevitably to be the main environmental conditions on supporting the growth of creative industries. The connected ways and operation mechanism are therefore becoming a significant foundation making those regional industries "latent clusters", which also perform as an important form of industry clusters.

This paper, from a view of the development of creative design, the organization of industrial resources and the mechanism of platform services, attempts to take the exploration of creative design as core content discussing the forms of creative clusters basing on regional industrial resources. Researches of this paper would like to provide a new method for the development of urban creative industry.
\end{abstract}

Keywords - creative clusters; connected clusters; connected mechanism; creative design

\section{INTRODUCTION}

Agglomeration of format elements around the regional industrial resources has played a pivotal role in economic transformation and the formulation of policies since Michael Porter' s introduction of clusters in 1990[1]. Industrial clusters generated by the enterprises benefitting from geographic proximity and collective interests turn into essential factors supporting the regional competition and economic growth, which is at the same time a key resource of economy agglomeration.

Structure transformation of industry development has rapidly produced a large number of Creative Parks basing on the foundation of industrial plant, which is now an important form of creative clusters and the main productive force. Taking Shanghai as an example, the city has owned 114 Cultural and Creative Industrial Parks at municipal level as of 2012. Data from the "2012 Shanghai Cultural and Creative Development Report" over the same period showed that, in 2011, the total output of cultural and creative industries reached 6429.18 millions RMB, accounting for a $10.02 \%$ proportion of GDP in Shanghai and contributing a $15.5 \%$ rate of its economic growth.

However, creative industry, either in terms of its industrial scale or economic contribution, still has large space to be promoted. And compared with the status and researches of foreign creative design industry, we are now lacking of deep researches on functional connected clusters constituted by related resources around the development of creative design. Further more, we still need to do more to accurately grasp the effect how creative industries working on the development of urban economy. This paper attempts to review the natural resources of urban industries and take creative design as the key point to explore the mechanism and developing path, through which industrial resources are able to forming functional connections.

\section{ThE CREATIVE Clusters From GEOGRAPHIC DIMENSION TO CONNECTED DIMENSION}

\section{A. Connected Clusters of Creative Industries}

As successful clusters regarded as "functional body" being able to "produce creative and get value", it means that connected clusters, benefiting from the wide and dense cooperative connections, own "industrial function". But geographic clusters, in contrast, are not associated with industrial function as purpose. Researches on clusters networking [2-4] pointed that, mere existence of creative agglomeration at geographic level is not enough for the benefits from clustering to emerge, as well as reflect its advantages. And another crucial ingredient to realize cluster is building effective links among local enterprises as collaborators, business partners and sources of innovation elsewhere, helping them establishing "vertical relationship from customers to suppliers, or horizontal connections from markets, technologies to marketing networks"[5].

It is significant for connected clusters to establish the "dense web of interaction and co-operation networking" through the delivery of creative design projects and the feedback of its value (including profit and social effects). Another expectation of the creative design projects is to generating a connected mechanism for creative industries operating independently and continuously. And in the operation (delivery) of creative design projects, three kinds of enterprises connected forms are included as following:

- Several creative projects being operated (delivery) in specific or related creative sectors completing the core work of creative and generating 
knowledge spillover, makes an inner connection taking shape;

- Processes that transforming creative prototype (ideas or services) to market value precipitate creative industries and some other complementary industries forming an outer connection;

- Local government, industrial organization and universities working as non-industrial pushing factors, help creative clusters establishing a functional connection during the process of creative design marketization.

\section{B. The Core Elements and Resourece Elements in Connected Clusters of Creative Industries}

1) Core elements - The exploration of creative content and the delievry of projects of creative enterprises.

The function of the core elements in creative industries is to produce creative prototypes and services, sometimes they also "jump" across the traditional industries as services providers, and on that way these core elements are able to construct orderly structure of creative development.

The knowledge influence and the keen insight into market of design institution and colony make them more effective in constructing creative projects, obtaining creative value and organizing necessary resources. Armed with these advantages, the core elements could deliver their projects to enterprises in the middle or lower reaches of creative industries or specific complementary enterprises we called the resource elements as well as share knowledge with them. On the other hand, companies distributed in the creative value chain like manufacturers, business traders, financing institutions, promote the connected relationships and organizational forms to emerge. Those small and mediumsized enterprises in creative design activities are often expected as a main force on creating large numbers of creative concepts and prototypes.

2) Resource elements - Outer resources beyond the creative value chain

Resources beyond the creative industries hammer at transforming the creative concepts and prototypes to market value and social public production. They often participate in the value chain by offering complementary resources for production, like paper-manufacturers and printers in publishing industry. In design industry, manufacturer, assembly firms, logistics are working as outer resources participate in design cluster.

Two forms of these elements are existed as follows:

a) Working as main roles in creative value chain. In this forms, they are expected owning the market strategic thinking as well as the fundamentals of product items planning. Fro example, traditional brand or manufacturers driven by the will of obtaining optimal market competition abilities, is likely to entrust the design enterprises executing the development of creative innovation and be the principal part of those projects.

b) Purchasing project proposals provided by design creative agencies or colony. In this form, enterprises of resources elements are likely to accept innovation projects along with making some changes on their management, operation or other aspects, becoming the customers of design creative agencies or colony.

3) Paltfrom services - The function of the social public resources

Platform consisting of social public resources are playing an increasing important role in creative clusters in recent years. In addition to create innovation environment and preferential policies, government and industrial organization are nowadays establishing specific department and services platform helping remove barriers to the collaboration between creative enterprises and other resources elements. Taking UK as an example, with the abolition of Regional Development agencies and the creation of Local Enterprise Partnerships, the government made a key policy that is the ongoing overhaul of the framework for regional development.

Some platforms and intermediary organizations cultivated by government have been effective links in the connection of different industrial resources. For example, the UK Creative industry bureau is a non-governmental organization supported by government since 1998, as of 2005, this bureau had already cultivated one hundred and twenty thousand creative enterprises.

Universities are also doing more to promote innovation in tech-intensive creative besides being the providers of creative talent. Basic researches promote the market process of creative and the industrial researches effectively reduce the costs of information retrieval and seeking opportunities.

Multiple investment and financing channels also gives the rapid development of creative industries a boost. The U.S. owning a multiple investment includes social venture capital, government supports funds, overseas capital and etc. Some enterprises like finance management, financing companies, legal consultancies could also participate in creative projects providing services for creative enterprises.

\section{TAKE CONTENT OF PROJECT AS TRANSMITTER TO CONSTRUCT THE CONNECTED DELIVERY OF CREATIVE Clusters}

Australian economist Jason Potts argues that many creative businesses organize their productive and innovative activities using open and collaborative connected models which are more suitable for highly dynamic competitive environments connecting with different productive elements[6]. The connection mechanism for different elements generating knowledge spillover through collaboration is increasingly drawing more attention. There is no doubt, however, that geographical proximity of industrial resources is only the sufficient but not necessary condition for creative clusters realizing its industrial function. And Competitive industrial agglomerations emerge through lengthy and organic processes that require the right mix of local resources and relationships[7].

The correlation effect modeled by the delivery of design creative projects could establish the "open and collaborative connected models" as well as the "lengthy and organic processes" for clustering. Creative projects, as an important 
way translating knowledge to productive forces and the main business of knowledge economy, enlarger investment under the condition of their success to meet the aspirations of the project's participators obtaining their value feedback. Further more, these projects could attract different elements to integrate and contribute capital and related resources ensuring successful operation of the projects. On the other hand, during the delivery of creative design project, communication among different enterprises around the same item could make wider collaboration and accelerate knowledge spillover. With the relationship of the anticipated value of projects and the anticipated function of resources, a stable connected cluster would be constructed.

1) Creative service projects characterized by project commissioned

Creative service projects characterized by project commissioned are long-term important formation in urban industries and creative industries, which concentrating mainly on R\&D design. In this type of projects, traditional brands or enterprises driven by the will for seeking market opportunities weld joint with creative companies and authorize them developing creative projects or offering related services of management and processing, which is often basing on their demand, capital, brand and techniques.

Successful construction of creative service projects depends on information capture of both parties involved. Traditional brands and enterprises are likely to select creative bodies as partner according to their industrial praise, abilities of innovation and executing, matching rate with their demand. In some large projects, creative bodies bid with project returns, creative prototypes (ideas, rendering and model) to intervene collaboration.

Final project contract determines roles and duties of both parties involved, which additional including request, progress, management, outcomes, investment (period and proportion) of the project. There is another condition that creative enterprises also involve their capital in project besides offering creative services, under which contrast need describing value assignment accurately by investment.

2) Creative dominanted projects with content of creative design

With the deepening of creative exploration, a mature operation mechanism has formed in fashion and some other industries. Creative bodies produce creative and then release it - by submitting creative content and project documents on a public releasing platform. They attract various industrial resources to give birth to the organizational structure of projects. Construction process of these projects is usually influenced by followings:

a) Establishing creative releasing platform with multiple elements. This platform is the core of condensing industrial resources and launched creative design projects. Creative bodies export prototype and project documents to the platform, and then different elements make a chose after assessment. The influence of platform and entrance of different resources create a symbiotic relationship for each other, for example, platform could offer more information, projects and resources opportunities for enterprises and more enterprises entrance could further increase the platform influence.

However, creative releasing platform should be developed independent basing on the profession of creative design industries. Support of policies, government credibility, brad effect and resources advantages of leading enterprises, creative and innovation abilities of creative bodies, technical and market capacities of complementary resources, researches from universities and talent cultivation, media and publicity are connected resources in assembling this creative publishing platform.

b) Establishing a third-party agency to evaluate creative content. It is important for creative project accepted by kinds of resources which is however elusive in creative design clusters. Establishing a third-party agency to evaluate creative content could raise efficiency connecting creative projects to different resources.

\section{The CONNECTED MeChanism OF CREATIVE CLUSTERS}

Aspiration of enterprises for value feedback makes chances of design projects and resources to be a main force on stabilizing the connection among companies. Small and middle-seized enterprises and individuals produce creative and release them in appropriate forms. Some other industrial elements dominating resources and attempting to obtain some market opportunities purchase their creative through three following ways. Merger and acquisition is one type of this purchasing and large corporate firms deserve the valuable creative content or the whole creative abilities of the small and middle-sized companies. Another type is only purchasing the content without its producers by bearing a certain cost of patents or copyright, and then they offer resources to complete the market process of the creative. The last type is the resource enterprises being partners of creative producers via investment or buying share, sometimes they would like to sign a contract with the creative individuals turning them working as their staff. From this point, they could exploit the creative abilities of the creative companies or individuals and engage in creative projects development around their resources during a certain time.

From an economic view, industrial resources would like to join in project construction with the expectation of obtaining value (profits, social influence) feedback. The core forces that ensuring the creative industries moving towards connected clusters is, therefore, satisfying the needs of different project participants' interests with a contract setting the feedback methods of value.

Constructers of creative projects need to think over the mechanism of value distribution meeting the needs of multistakeholder. Factors like proportion of investment in projects and shares held by resources enterprises should be regarded as the key indicators when drawing up the mechanism of value distribution. For those noninvestment participators, projects constructers have to take the cost of projects commission acquiesced in the specific sectors into account. In a general case, value feedback expresses 
negative correlation as the elements deviating from the core level of creative and market. It is worth explicating here, that a dominant position of creative enterprises in the creative projects is making for the projects working around the creative core, which at the same time, doing a favor of stimulating the innovation performance of creative enterprises in creative projects (like generating additional knowledge spillover).

Another kernel of value distribution in connected mechanism is making appropriate matching principle of value. Apart from the feedback to participators, cost consuming in continuous operation, including labor cost, maintaining of software and hardware, market promotion and so on, are inevitable. Some projects with huge value or market space could also lead to a phenomenon called "project spillover", triggering behaviors like extend exploration of project market or development of complementary goods of creative product and services.

\section{CONCLUSION}

Researches mentioned above show that mechanism in the development and operation of creative clusters seems to be more particular than other industry clusters. Owing to the diversity of creative projects and multifarious need of resources, it is difficult to establish stable collaboration, which is common in traditional clusters, in creative clusters. Furthermore, there have already been lots of aggregation at geographical level in some areas, but the lacking of awareness for the enterprises that they have clustered as well as the existing of the "weak links" among industrial elements, are hindering the formation of industrial function of these creative collaboration.
It is fortunate to find in some case studies that, government and clusters dominant power are paying more attention on those "hidden clusters" [8] and bringing them into organizational creative clusters. It is far better to indentify whether there are any latent clusters hidden in regions or localities that could benefit from networking and awareness-raising[9]. Increasing the visibility of such clusters with preferential policies and delivery of creative projects and value would probably make them contributing more to local competition, innovation and economy development[7].

\section{REFERENCES}

[1] Machael E. Porter. The competitive advantage of nations[M]. London: Macmillan,1990.

[2] Glaeser E L.Are cities dying[J]. The Journal of Economic Perspectives, 1998, 12(2): 139-136.

[3] Charles Landary. The creative city. A toolkit for urban innovations[M].Earthscan Publications Ltd, London, 2000.

[4] Dahl M S, Pedersen C R. Knowledge flows through informal contacts in industrial clusters: Myths or realities[J]. Research Policy, 2004, 33(10): 1673--1686.

[5] Machael E. Porter. Clusters and the new economics of competition[J] Harvard Business Review, 1998, vol. 76 Issue 6, p77. 2009 : 121-127.

[6] Potts J. and Mornson K.. Nudging innovation. NESTA report, 20008.

[7] Caroline Chapain, Phil Cooke, Lisa De Propris, Stewart MacNeill and Juan Mateos-Garcia. Creative clusters and Innovation. NESTA report, 2010.

[8] Iammarino, S. and McCann, P. The structure and evolution of industrial clusters: Transactions, technology and knowledge spillovers. Research Policy, 2006,35(7): 1018-1036.

[9] Jesper Christiansen, Laura Bunt. Innovation in Policy: Allowing for Creativity, Social Complexity and Uncertainty in Public Governance. NESTA report, 2012 